\title{
Percutaneous tracheostomy without bronchoscopy a safe procedure
}

\author{
Emídio Jorge Santos Lima* \\ Intensivist, Intensive Care Unit of Camaçari General Hospital, Brazil
}

\begin{abstract}
Introduction: Tracheostomy is a common procedure in ICU, particularly as an approach for weaning from mechanical ventilation. In mid-1980s percutaneous tracheostomy (PCT) was introduced as a less invasive alternative for the standard surgical tracheostomy. A tracheostomy facilitates weaning from mechanical ventilation, in long-term ventilated patients, by improving airway cleaning, better patient comfort, and decreasing airway resistance. Prolonged mechanical ventilation has as main complication ventilator-associated pneumonia. In such case early tracheostomy may reduce that complication.

Methods: We analyzed prospectively 104 adult patients mean age of 53 years who underwent PCT at our ICU between 2012 and 2014 . Inclusion criteria were: age > 18 years and indication for tracheostomy. Exclusion criterion was technical contraindication for PCT. All the PCT were performed at bedside using Ciaglia technique.

Results: 104 patients, reasons for PCT were weaning failures in 82 (78.85\%) and airway protection in $22(21.15 \%)$. The most frequent reasons for admission to the ICU were: pneumonia in 25 (24\%); sepsis in 19 (18\%), and drug intoxication in 7 (6.7\%). The mean duration of preceding translaryngeal intubation was 9 days. The mean length of ICU stay was 14 days. We observed one complication in one patient; it was a tracheal stenosis. Sixty six patients (63\%) died during their stay in the ICU. These deaths were unrelated to the PCT, but related to severe organ dysfunction. Thirty eight patients (36.54\%) survived and was discharged from the hospital,
\end{abstract} 37 was decannulated.

Conclusion: PCT, in our series, was a safe and practical procedure for bedside management of critical patients.

\section{Introduction}

Tracheostomy is a common procedure in critical care setting, particularly as an approach for weaning from mechanical ventilation after several weaning failures [1].

In 1909, Jackson described the standard surgical tracheostomy and in mid-1980s percutaneous tracheostomy (PCT) was introduced as a less invasive alternative for the standard surgical tracheostomy and over the last decade has gained worldwide acceptance [2,3].

A tracheostomy facilitates weaning from mechanical ventilation, in long-term ventilated patients, by improving airway suctioning and cleaning, better patient comfort, decreasing airway resistance and respiratory work $[1,4]$. Prolonged mechanical ventilation (MV) in intubated patients has as main complications: ventilator-associated pneumonia, side effects related with prolonged sedation and laryngeal injury. In such cases early tracheostomy may reduce these complications [1].

Some complications are related to tracheostomy mostly: bleeding, tracheal stenosis and infection. Several studies have shown that PCT is a safe, practical and fast procedure and it is associated with lower morbidity than standard surgical tracheostomy $[5,6]$. The aim of this study was to analyze the safety of PCT performed at the bedside in one intensive care unit (ICU).

\section{Methods}

We evaluated prospectively 104 consecutive adult patients ( 65 men, 39 women) with a mean age of 53 years who underwent PCT at our ICU
(Camaçari General Hospital/Brazil) between March 2012 and February 2014. The study was conducted in a general ICU (7 beds). Inclusion criteria were: age more than 18 years and indication for tracheostomy (two or more weaning failures, need for airway protection). Exclusion criteria included technical contraindication to PCT like enlarged thyroid gland and coagulopathy. The ethics committee approved the study. Informed consent was obtained from all the patients or the patient's family if the patient was not mentally capable. All the PCT were performed at bedside by an experienced physician using Ciaglia progressive dilatational tracheostomy technique, Ciaglia Percutaneous Tracheostomy Introducer Set; William Cook [3]. Patients received intravenous analgesia and sedation (Midazolam, Ketamine or Propofol associated with Fentanyl). The patient was positioned in the ICU bed with the neck hyperextended and the operative area prepared. The patient's lungs were ventilated with $100 \%$ oxygen. The tracheal tube was repositioned above the site of the proposed tracheostomy. Blood pressure, cardiac rate and rhythm and pulse oximetry were continuously monitored during the PCT. A 2 -cm horizontal incision was made between the cricoid cartilage and the suprasternal notch in the area between the first and second, or the second and the third tracheal rings. The trachea was then punctured in the midline by a cannula. Correct positioning was confirmed by easy aspiration of air. The guidewire was

Correspondence to: Emídio Jorge Santos Lima, Street Manoel Gomes de Mendonça, no. 207, apt 104, ZIP CODE 41810820, Pituba, Salvador BA/Brazil, Tel: + 5571 988286059; E-mail: emidio.lima@gmail.com

Received: May 12, 2016; Accepted: June 03, 2016; Published: June 06, 2016 
then passed and the percutaneous dilators, starting with 14 Fr dilator increasing to a size of $38 \mathrm{Fr}$ (single dilatator-Blue Rhino), finally the tracheostomy tube was placed through the guidewire, it was then took out and the tube fixed by stitches. All patients had chest X-rays performed after the tracheostomy. The first change of the tracheostomy tube was performed after 5 days. Intraprocedural and postprocedural complications were recorded. All patients were followed during hospitalization and 1 year after the discharge.

\section{Results}

Of the 104 patients enrolled in the study, reasons for PCT were weaning failures in $82(78.85 \%)$ and airway protection in $22(21.15)$. The most frequently reasons for admission to the ICU were: pneumonia in 25 patients (24\%), sepsis in 19 patients (18.3\%) and drug intoxication in 7 (6.7\%), Table 1 . The mean duration of preceding translaryngeal intubation was 9 days. The mean length of ICU stay was 14 days.

We observed one complication in one patient; it was a tracheal stenosis that was successfully treated by surgery. In our series of 104 patients, there was no bleeding or accidental decannulation and there were no deaths directly related to the procedure.

A total of 66 patients (63\%) died during their stay in the ICU. These deaths were unrelated to the PCT, but related to severe organ dysfunction. Of the 66 deaths, shock in 25 (37.9\%), multiple organ dysfunction syndrome in $19(28.8 \%)$ and acute respiratory distress syndrome $9(13.6 \%)$ were the most frequent causes.

A total of 38 patients (36.5\%) survived and was discharged from the hospital of these 37 was decannulated. In one patient, with severe brain injury after stroke, tracheostomy tube was maintained for airways protection although successfully weaning from mechanical ventilation.

\section{Discussion}

Percutaneous tracheostomy was introduced by Ciaglia in 1985 and progressively gained worldwide acceptance mostly at intensive care setting $[1,3]$. Today $60 \%$ of the tracheostomies performed at ICU are made by percutaneous technique. In relation to the standard surgical tracheostomy, PCT is more practical, faster, bedside technique and associated with fewer complications [1,7]. In a meta-analysis involving 1212 patients, PCT was associated with lower incidence of hemorrhage, wound infection and death compared with surgical standard tracheostomy [5]. According to literature complications related to PCT are rare, $3 \%-4 \%[1,5,7]$. In our study occurred 1 complication in one patient $(0.96 \%)$ it was a tracheal stenosis. Bleeding is the most frequent complication associated with PCT, although major bleeding is uncommon [8]. In our series of 104 patients we didn't have hemorrhage

Table 1. Reasons for ICU admission in 104 patients undergoing percutaneous tracheostomy.

\begin{tabular}{|l|c|c|}
\hline Reason for ICU admission & No. of patients & $\mathbf{\%}$ \\
\hline Pneumonia & 25 & 24 \\
\hline Severe sepsis & 19 & 18.3 \\
\hline Drug intoxication & 7 & 6.7 \\
\hline Chronic obstructive pulmonary disease & 6 & 5.8 \\
\hline Cardiac arrest & 6 & 5.8 \\
\hline Ischaemic stroke & 4 & 3.8 \\
\hline Peritonitis & 4 & 3.8 \\
\hline Asthma & 3 & 2.9 \\
\hline Pulmonary contusion & 3 & 2.9 \\
\hline Miscellaneous & 27 & 26 \\
\hline Total & 104 & 100 \\
\hline
\end{tabular}

complication; it is explained by minimal disruption of tissues and the tamponade effect of the tightly fitting tracheostomy tube. According to a large cohort of 800 patients who underwent PCT, displacement of the tracheal tube occurred in only one patient [7]. Among our patients we didn't have displacement of tracheal tubes because these were systematically fixed with stitches.

Death related to PCT is a rare event; rates of $0 \%$ and $0.35 \%$ are described in the literature $[1,7,8]$. In one study of 572 patients, who underwent PCT, occurred 2 deaths related to the procedure due to trachea-innominate fistulae, mortality of $0.35 \%$ [8]. In our study there weren't deaths directly related to PCT, they were attributed to severe illnesses, mostly sepsis and organs dysfunction.

There is a relationship between PCT learning curve and complications. Morbidity and mortality increase when inexperienced physicians perform PCT. According to a great prospective cohort of 800 patients, more than 5 attempts were considered sufficient to learn how to perform this procedure and were associated with a decrease in perioperative complications [7].

Originally Ciaglia introduced PCT without bronchoscopy; posteriorly it was added to guide the physician in performing the procedure. Today the use of bronchoscopy is optional and there is no difference in the rate of complications with and without bronchoscopy $[3,7]$.

Several studies have shown that PCT facilitates weaning from mechanical ventilation decreasing duration of mechanical ventilation, pneumonia and mortality $[1,3,9-11]$. In our series of patients PCT resulted in $100 \%$ successfully weaning from mechanical ventilation and $99 \%$ of decannulation.

\section{Conclusion}

Percutaneous tracheostomy without bronchoscopy, among our series of patients, was a safe and practical procedure and can be considered a routine approach in the bedside management of critical long-term ventilated patients.

\section{Acknowledgements}

The study is performed at Camaçari General Hospital, Brazil with the help of the Institution's Ethics Committee i.e., Comitê de Ética da Secretaria de Saúde do Estado da Bahia (SESAB), Brazil. The reference number of the Ethics Committee that approved the study is 47084014700000052 .

\section{References}

1. Flaatten H, Gjerde S, Heimdal JH, Aardal S (2006) The effect of tracheostomy on outcome in intensive care unit patients. Acta Anaesthesiol Scand 50: 92-98. [Crossref]

2. Jackson C (1909) Tracheostomy. Laryngoscope 19: 285-90.

3. Ciaglia P, Firsching R, Syniec C (1985) Elective percutaneous dilatational tracheostomy. A new simple bedside procedure; preliminary report. Chest $87:$ 715-9.

4. Plummer AL, Gracey DR (1989) Consensus conference on artificial airways in patients receiving mechanical ventilation. Chest 96: 178-180. [Crossref]

5. Delaney A, Bagshaw SM, Nalos M (2006) Percutaneous dilatational tracheostomy versus surgical tracheostomy in critically ill patients: a systematic review and metaanalysis. Crit Care 10: R55. [Crossref]

6. Higgins KM, Punthakee X (2007) Meta-analysis comparison of open versus percutaneous tracheostomy. Laryngoscope 117: 447-454. [Crossref]

7. Díaz-Regañón G, Miñambres E, Ruiz A, González-Herrera S, Holanda-Peña M, et al. (2008) Safety and complications of percutaneous tracheostomy in a cohort of 800 mixed ICU patients. Anaesthesia 63: 1198-1203. [Crossref] 
8. Dempsey GA, Grant CA, Jones TM (2010) Percutaneous tracheostomy: a 6 yr prospective evaluation of single tapered dilator technique. British Journal of Anaesthesia 105: 782-8.

9. Ferreira LL, Cavenaghi OM (2011) Early tracheostomy in weaning from mechanical ventilation. Rev Bras Clin Med 9: 432-6.
10. Cosgrove JF, Carrie S (2015) Indications for and management of tracheostomy. Surgery. 33: 172-179.

11. Nieszkowska A, Combes A, Luyt CE, Ksibi H, Trouillet JL, et al. (2005) Impact of tracheotomy on sedative administration, sedation level, and comfort of mechanically ventilated intensive care unit patients. Crit Care Med 33: 2527-2533. [Crossref]

Copyright: C2016 Lima EJS. This is an open-access article distributed under the terms of the Creative Commons Attribution License, which permits unrestricted use, distribution, and reproduction in any medium, provided the original author and source are credited. 